\title{
Nicole Martin: Art as an Early Intervention Tool for Children with Autism
}

\author{
Jessica Kingsley Publishers, London, UK, 2009, 156 pp, ISBN 978184905807 0, \$18.95 \\ (Paper)
}

Sheila Christopher

Published online: 17 March 2010

(C) Springer Science+Business Media, LLC 2010

Early Intervention Tool for Children with Autism by Nicole Martin is just the right book for busy parents, a practical reference for psychologists, teachers, occupational therapists, sensory integration therapists and anyone working with a child on the autism spectrum. It will be of particular interest to all those professionals working with autistic children and specialists in other communication disorders. Art therapy is a psychological discipline that specializes in using visual art making and the creative process to help clients bring about therapeutic change. There are resources for children with autism in myriad forms, and art therapy could be the right fit for the child with autism and "art can provide a way to express what is more complicated".

Nicole Martin, a qualified art therapist herself writes from a professional and personal perspective. Setting up a work space, basic art materials required and ideas and suggestions for managing challenging behaviour are presented clearly in the book. Martin provides a comprehensive overview of the techniques of art therapy presented in a precise, interesting format for easy reading. The experience of the author in using art as a therapeutic tool adds to the authenticity of the work thus making it a reliable, authoritative, and appropriate source of information.

Art therapists focus on several areas: increasing communication skills, developing a sense of self, relationship building, and facilitating sensory integration. This classic book answers questions about using art as a therapeutic tool for children with autism. Early childhood is the most critical period of learning for children. Therapeutic art can be a useful tool to delve into a child's imaginations and

S. Christopher $(\bowtie)$

Department of Rehabilitation Science, Holy Cross College,

Tiruchirappalli 620 002, India

e-mail: sheila627@gmail.com enable them to express their thoughts and feelings. Martin offers practical advice on helping a child move past scribbling, organizing a child's environment for maximum comfort and relaxation, and providing physical and sensory support. Martin describes observable differences of the autism-related style of art making and highlights the 'unique beauty and style' of the art made by people with autism. Artwork characteristics across the autism spectrum are clearly illuminated, identifying the subtle differences between the art of typically developing individuals and that of children with autism. Art therapy provides a supportive environment that encourages the child's interests and works on the deficit areas.

Art is both visual and appealing, making it an excellent mechanism to initiate learning. Throughout the book, Martin emphasizes how art therapy works as an integral part of overall management and treatment approaches to autism. The author presents a range of case studies of art therapy with individual autistic children to bring to light the use of practical interventions and their outcome. Martin also suggests that art therapy provides an avenue for nonverbal expression and enables the children increase their communication and social skills. As the book progresses, one can find the tempo of the book shifting from art as being purely recreational to being therapeutic as well. The simple examples, a detailed list of art projects, apt case studies, spiced with illustrations and ultimately a comprehensive list of resources at the end of the book add to the wholesome nature of the book. Her narrative is clear and lucid. The author presents word-pictures of scenes and pictures of art drawn by children themselves, by giving specific details that appeal to the five senses. 